\title{
Antidiabetic and Antidyslipidemic Properties of GOA-111, a Mixture of Gymnema sylvestrae, Ocimum sanctum and Azadirachta indica Extract in the Ratio of 1:1:1 Studied in High Fat Diet Fed- Low Dose Streptozotocin Induced Experimental Type 2 Diabetes in Rats
}

\section{Sangeetha Sathyanarayan * and K. Sadasivan Pillai}

Department of Cellular \& Molecular Biochemistry, Frontier Mediville (Affiliated to University of Madras)(A unit of Frontier Lifeline \& Dr. K. M. Cherian Heart Foundation), Chennai 600101,Tamilnadu, India.

\begin{abstract}
Diabetes mellitus emerges from multiple biochemical and cellular impairments, including decreased insulin secretion from the pancreatic $\beta$ cells and impaired insulin action in peripheral tissues. The present study was systematically carried out to evaluate antidiabetic and antidyslipidemic properties of GOA-111,a herbal extract containing a mixture of Gymnema sylvestrae, Ocimum sanctum leaves and seed kernel of Azadirachta indica in the ratio of 1:1:1 in ameliorating both the primary and secondary complications of type 2 diabetes mellitus in high fat diet fed low dose streptozotocin induced diabetic rats. Experimental type 2 diabetes was induced with a low dose streptozotocin in rats fed on a high fat diet. Diabetic rats were treated with three different doses GOA $111 \quad(150,300$ and $450 \mathrm{mg} / \mathrm{Kg}$ b.wt/rat/day) for 30 days. The toxicological parameters such as AST, ALT and ALP were assayed. Biochemical parameters such as fasting blood glucose, glycosylated hemoglobin, insulin, insulin resistance and lipid profile were measured. Oral treatment with GOA 111 significantly decreased the elevated levels of fasting glucose, glycosylated hemoglobin, AST, ALT and ALP. The insulin level was improved in insulin resistant dia betic rats. GOA 111 also normalized the lipid profile. Though the results showed a dose dependent impact on the parameters, a dose of $300 \mathrm{mg} / \mathrm{Kg} \mathrm{B} / \mathrm{W} / \mathrm{rat} / \mathrm{day}$ GOA 111 exerts maximum potential anti-hyperglycemic and antidyslipidemic effects in HFD/STZ-induced type 2 diabetic rats.
\end{abstract}

Keywords: GOA 111; High fat diet; Streptozotocin; antidiabetic; antidyslipidemic.

Article Info: Received 11 July 2019; Review Completed 17 August 2019; Accepted 21 August 2019; Available online 30 Aug 2019

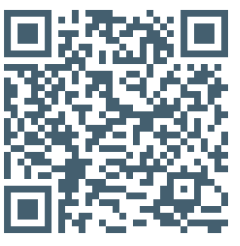

Cite this article as:

Sathyanarayan S, Pillai KS, Antidiabetic and Antidyslipidemic Properties of Goa-111, a Mixture of Gymnema Sylvestrae, Ocimum Sanctum and Azadirachta Indica Extract in the Ratio of 1:1:1 Studied in High Fat Diet Fed- Low Dose Streptozotocin Induced Experimental Type 2 Diabetes in Rats, Journal of Drug Delivery and Therapeutics. 2019; 9(4A):115-121 http://dx.doi.org/10.22270/jddt.v9i4-A.3394

Sangeetha Sathyanarayan, Department of Cellular \& Molecular Biochemistry, Frontier Mediville (Affiliated to University of Madras)(A unit of Frontier Lifeline \& Dr. K. M. Cherian Heart Foundation), Chennai 600101,Tamilnadu, India.

\section{INTRODUCTION}

Type 2 diabetes mellitus which is caused due to insulin resistance is closely related to obesity and sedentary life style. Type 2 diabetic individuals are more prone to develop both microvascular and macrovascular complications 1. Insulin resistance and impaired insulin secretion are the core defects in T2DM; however other pathophysiological conditions ultimately results in the dysregulation of glucose metabolism. Though, the available therapeutic measures for the treatment of T2DM are sufficient, search for drugs that improve insulin sensitivity, diminish pancreatic $\beta$-cell dysfunction without any detrimental side effects is necessary.

Natural compounds preferentially from plant sources provide various pharmacological effects due to the presence of phytochemicals ${ }^{2}$. Plant based drugs are more affordable ISSN: 2250-1177 and effective with less side-effects when compared to other therapies. Pharmaceutical research is increasingly leaning towards the discovery of new antidiabetic drugs from natural products targeting pathways or components associated with type 2 diabetes mellitus (T2DM) pathophysiology3. Herbal remedies are preferred in traditional systems of medicine, despite the fact of less scientific evaluation for their toxicity and efficacy. Though, a number of individual herbs have been experimentally reported to exert antidiabetic effects, limited studies have been carried out on polyherbal formulations. Herbal compounds contain a combination of several plant products which possess synergistic antidiabetic effects to enhance the desired pharmacological actions ${ }^{4}$.

G. sylvestre is one of the indispensable medicinal plants used in Ayurvedic system of medicine for the treatment of diverse 
diseases. It is used in food additives against obesity 5,6. Ocimum sanctum belongs to the family of Lamiaceae and is commonly known as Thulasi/Tulsi in India. It is widely grown in all regions and is considered as the sacred plant of India. In the Indian sub-continent, fresh leaves of this plant are most commonly used for the treatment of cough, cold, abdominal pain, skin diseases, arthritis, painful eye diseases, measles, and diarrhea. The preclinical evaluation on various extracts of different parts of Ocimum sanctum showed antioxidant, anti-cancer, anti-diabetic, anti-bacterial, hepatoprotective and cardioprotective actions $7,8,9,10,11$.

Azadirachta indica, commonly known as neem, has attracted worldwide prominence in recent years, owing to its wide range of medicinal properties. Neem has been extensively used in Ayurveda, Unani and Homoeopathic medicine and has become a cynosure of modern medicine ${ }^{12}$. The tree and its extracts have also been reported to possess insecticidal, anti-viral, anti-fungal and anti-bacterial properties ${ }^{13}$.

In view of the above reported medicinal properties, the present study was designed to evaluate the antidiabetic and antidyslipidemic properties of a mixture of G.sylvestrea, O.sanctum and A.indica (GOA 111) in high fat fed low dose streptozotocin induced type 2 diabetic rats.

\section{MATERIALS AND METHODS}

\section{Plant Material}

A mixture of the leaves of G.sylvestrea, O.sanctum and the seed kernel of A.indica in the ratio of $1: 1: 1$, was used in the present study.

\section{Experimental Animals}

Male albino wistar rats weighing 150-170g were purchased and maintained in Nandha College of Pharmacy, Erode. The rats were housed in polypropylene cages lined with husk They were maintained at an ambient temperature of $25 \pm 2^{\circ} \mathrm{C}$ and $12 / 12 \mathrm{~h}$ of light/dark cycle. Animals were fed with standard commercial rat chow (Hindustan Lever Ltd) and water ad libitum and housed under standard environmental conditions throughout the study. The experiments were strictly conducted according to the ethical norms approved by the Ministry of Social Justices and Empowerment, Government of India and Institutional Animal Ethics Committee Guidelines [IAECNO: NCP/IAEC/2018-19/19].

\section{High fat diet fed streptozotocin induced diabetes}

The rats were divided into two dietary regimens by feeding either normal or high fat diet (HFD) for the initial period of two weeks ${ }^{14}$. The composition of HFD is powdered NPD $365 \mathrm{~g} / \mathrm{kg}$, Lard $-310 \mathrm{~g} / \mathrm{kg}$, Caseine $-250 \mathrm{~g} / \mathrm{kg}$, cholesterol $10 \mathrm{~g} / \mathrm{kg}$, vitamin and mineral mix $-60 \mathrm{~g} / \mathrm{kg}$, DL-methionine $3 \mathrm{~g} / \mathrm{kg}$, Yeast powder $-1 \mathrm{~g} / \mathrm{kg}, \mathrm{NaCl}-1 \mathrm{~g} / \mathrm{kg}$. After two weeks of dietary manipulation, the groups of rats fed with HFD was injected intraperitoneally (IP) with a low dose of STZ (35 $\mathrm{mg} / \mathrm{kg} \mathrm{b.w)} \mathrm{dissolved} \mathrm{in} 0.1 \mathrm{M}$ cold citrate buffer, $\mathrm{pH} 4.5$ ). One week after STZ injection, the rats were screened for blood glucose level. Rats having fasting blood glucose (FBG) $>250 \mathrm{mg} / \mathrm{dl}$ that exhibited random hyperglycaemia and glycosuria were selected for the experiment. The rats continued to feed on their respective diets until the end of the experiments.

\section{Designing of Experimental Animals}

The rats were divided into six groups $(n=6)$ :

Group I - Control rats.

Group II - HFD fed - low dose STZ induced type 2 diabetic rats.
Group III - Diabetic rats orally treated with GOA1:1:1(150 mg/ kg b.w./rat/day).

Group IV - Diabetic rats orally treated with GOA1:1:1(300 mg/ kg b.w./rat/day).

Group V - Diabetic rats orally treated with GOA1:1:1(450 mg/ kg b.w./rat/day).

Group VI - Diabetic rats orally treated with a standard drug, metformin (50 mg/ $\mathrm{kg}$ b.w./rat/day) in aqueous solution.

At the end of the treatment period, the rats were allowed to fast overnight before they were anesthetized and sacrificed by cervical decapitation. The blood was collected with and without anticoagulants for plasma and serum separation, respectively.

\section{Oral Glucose Tolerance Test}

Oral glucose tolerance test (OGTT) test was performed in all the groups of animals on the day prior to sacrifice. Blood samples were obtained from the lateral tail vein of rat. Successive blood sample was taken at 0, 30, 60, 90 and 120 minutes following the administration of $2 \mathrm{~g} / \mathrm{kg} \mathrm{b.w}$. of glucose solution.

\section{Biochemical parameters}

Glucose was measured by glucose oxidase method ${ }^{15}$. Plasma was separated and used for insulin assay using ELISA kit for rats (Linco Research, Inc., USA). Levels of hemoglobin and glycosylated hemoglobin were estimated according to methods of Drabkin and Austin, 1932; Nayak and Pattabiraman, (1981) respectively ${ }^{16,17}$.

Aspartate transaminase(AST), Alanine transaminase (ALT)and Alkaline phosphatase (ALP) were assayed by the method of King 18a,b.

\section{Determination of homeostasis model of insulin assessment}

Insulin abnormality cannot be accurately detected by a single determination of insulin or glucose levels. Hence, insulin resistance was evaluated by homeostasis model assessment of insulin resistance (HOMA-IR) ${ }^{19}$.

HOMA-IR = Fasting insulin level $(\mu \mathrm{U} / \mathrm{ml}) \mathrm{X}$ Fasting blood glucose (mg/dl) / 405

\section{Lipid profile studies}

Cholesterol content, triglycerides, and free fatty acids in serum tissues were estimated 20.21.22. Phospholipid concentration was estimated by the method of Bartlett ${ }^{23}$ by digestion with perchloric acid and the phosphate liberated was estimated by the method of Fiske and Subbarow ${ }^{24}$.

\section{Statistical analysis}

The results were expressed as mean \pm S.E.M of six rats per group and statistical significance was evaluated by one-way analysis of variance (ANOVA) using SPSS (version 16) program followed by LSD. Values were considered statistically significant when $\mathrm{p}<0.05$.

\section{RESULTS AND DISCUSSION}

The development of animal model for type 2 diabetes which reflect the natural metabolic characteristics of human T2DM is very challenging. Feeding high fat diet results in insulin resistance 25. Furthermore, administration of low dose STZ mediates mild impairment to pancreatic $\beta$-cells which is parallel to the metabolic characteristics of the later stage of T2DM. A combination of HFD and low dose of STZ (45 
$\mathrm{mg} / \mathrm{kg}$ ) injection is used to generate a rat model that mimics the clinical features of type- 2 diabetes in humans ${ }^{26}$.

Metformin, an oral antidiabetic drug acts primarily at the liver by reducing glucose output and, secondarily, by facilitating glucose uptake in the peripheral tissues, chiefly in muscle 27 . Hence, in the present study, metformin was used as a standard drug to compare the efficacy of the GOA 111 in ameliorating hyperglycemia and its associated complications.

The levels of blood glucose in certain durations after the oral administration of glucose $(2 \mathrm{~g} / \mathrm{Kg}$ body weight) in normal and experimental group of rats is depicted in Figure 1.

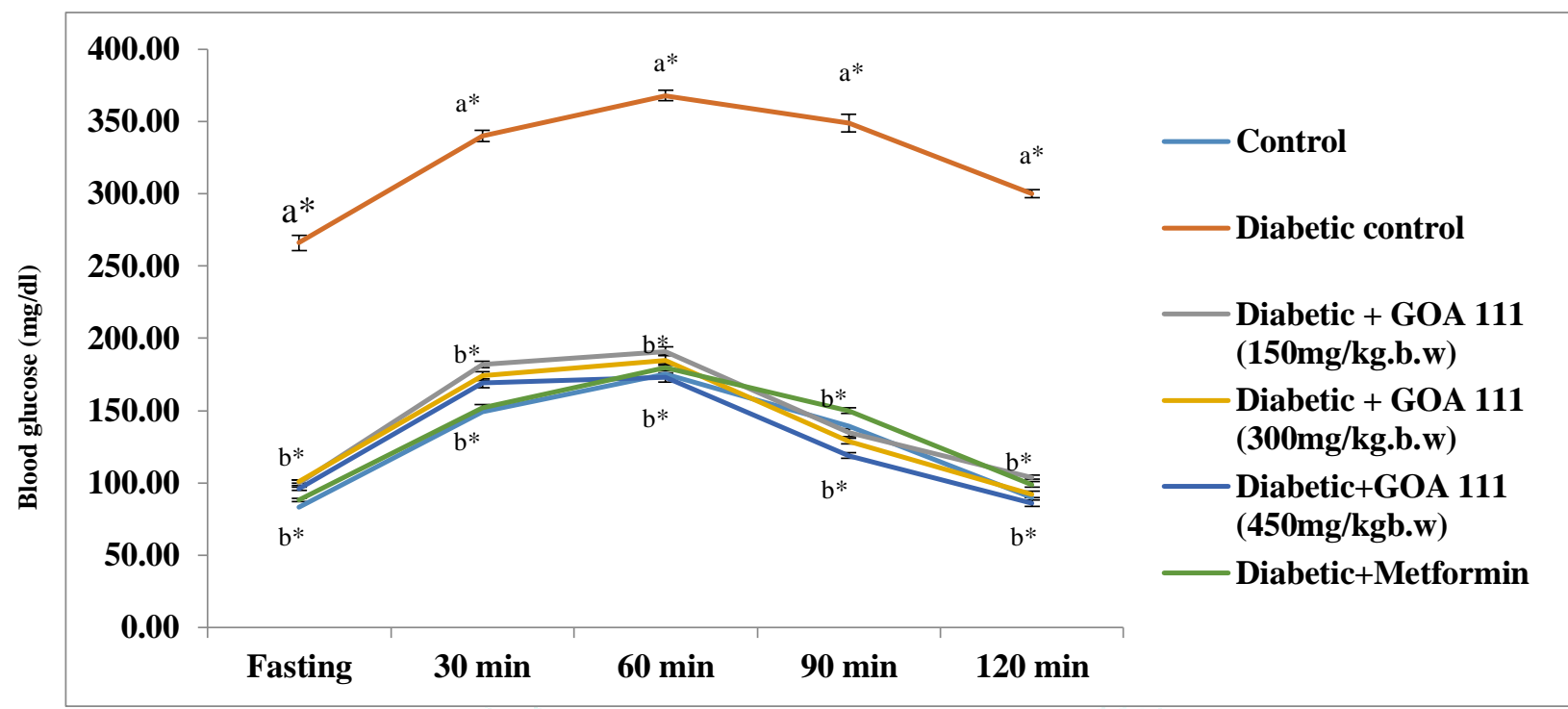

Values are given as mean \pm SEM for groups of six rats in each. One way ANOVA followed by post hoc test LSD.

Values are statistically significant at $* \mathbf{p}<0.05$; and are compared with ${ }^{\mathrm{a}}$ Control rats; ${ }^{\mathrm{b}}$ Diabetic control rats

\section{FIGURE 1: EFFECT OF GOA 111 ON BLOOD GLUCOSE LEVEL AFTER RECEIVING AN ORAL GLUCOSE CHALLENGE}

Impaired fasting glucose (IFG) has been commonly encountered in primary care since fasting plasma glucose test (FG) becomes the most popular screening test for diabetes mellitus (DM). Individuals with abnormal glucose regulation between normal glucose homeostasis and DM are identified, defined by an elevated FG level28. OGTT is a measure of effective glucose utilization by the system and it is often performed for early diagnosis of diabetes ${ }^{29}$. It is considered as a more sensitive measure of early abnormalities in glucose homeostasis than fasting plasma glucose or glycosylated hemoglobin.. In control rats, the blood glucose level reached the maximum peak at $60 \mathrm{~min}$ after an oral glucose load and then it was gradually reverted back to near normal levels after $120 \mathrm{~min}$. In STZ-induced diabetic rats, the peak increase in blood glucose concentration was observed after 60 min and remained high over the next $60 \mathrm{~min}$. Oral administration of GOA 111 at the dosage of $300 \mathrm{mg}$ and $450 \mathrm{mg} / \mathrm{kg} . \mathrm{bw} / \mathrm{rat} /$ day to HFD-STZ induced diabetic rats showed significant decrease in blood glucose concentration at 60 and 120 min when compared with diabetic control. However, only a moderate reduction in blood glucose levels were observed in the rats treated with $150 \mathrm{mg} / \mathrm{kg} . \mathrm{bw} / \mathrm{rat} /$ day. The marked decrease in the blood glucose levels after an oral glucose challenge in diabetic rats treated with GOA 111 indicating the beneficial effect of GOA 111in maintaining glucose homeostasis.

The effect of GOA 111 on the levels of fasting blood glucose, fasting plasma insulin and glycosylated hemoglobin (HbA1c $\%$ ) in HFD/STZ diabetic rats is shown in Table 1.

Table 1: Shows the levels of blood glucose, hemoglobin, glycosylated hemoglobin (HbA1c), plasma insulin and urine sugar in control and experimental groups of rats.

\begin{tabular}{|l|l|l|l|l|l|}
\hline Groups & Fasting Blood glucose & Hemoglobin & HbA1c & Insulin & Urine sugar \\
\hline Control & $84.60 \pm 2.80$ & $14.50 \pm 0.32$ & $6.38 \pm 0.15$ & $15.50 \pm 0.24$ & Nil \\
\hline Diabetic control & $269.90 \pm 3.30 \mathrm{a}^{*}$ & $8.31 \pm 0.51 \mathrm{a}^{*}$ & $13.18 . \pm 0.20^{\mathrm{a}^{*}}$ & $10.38 \pm 0.18^{\mathrm{a}^{*}}$ & +++ \\
\hline $\begin{array}{l}\text { Diabetic + GOA 111 } \\
(150 \mathrm{mg} / \text { Kg.b.w })\end{array}$ & $111.00 \pm 1.93^{\mathrm{b}^{*}}$ & $11.90 \pm 0.39 \mathrm{~b}^{*}$ & $8.26 \pm 0.20^{\mathrm{b}^{*}}$ & $11.00 \pm 0.28 \mathrm{~b}^{*}$ & + \\
\hline $\begin{array}{l}\text { Diabetic + GOA 111 } \\
(300 \mathrm{mg} / \text { Kg.b.w })\end{array}$ & $99.30 \pm 2.80 \mathrm{~b}^{*}$ & $12.61 \pm 0.45 \mathrm{~b}^{*}$ & $7.50 \pm 0.14 \mathrm{~b}^{*}$ & $12.40 \pm 0.30 \mathrm{~b}^{*}$ & Nil \\
\hline $\begin{array}{l}\text { Diabetic + GOA 111 } \\
(450 \mathrm{mg} / \text { Kg.b.w })\end{array}$ & $97.30 \pm 2.73 \mathrm{~b}^{*}$ & $12.50 \pm 0.46 \mathrm{~b}^{*}$ & $7.60 \pm 0.17 \mathrm{~b}^{*}$ & $12.43 \pm 0.24 \mathrm{~b}^{*}$ & Nil \\
\hline Diabetic+metformin & $88.00 \pm 2.10^{\mathrm{b}^{*}}$ & $13.50 \pm 0.39 \mathrm{~b}^{*}$ & $7.00 \pm 0.19 \mathrm{~b}^{*}$ & $13.55 \pm 0.29 \mathrm{~b}^{*}$ & Nil \\
\hline
\end{tabular}

Units: $\mathrm{mg} / \mathrm{dl}$ for blood glucose, $\mathrm{g} / \mathrm{dl}$ for hemoglobin, \% hemoglobin for HbA1c, $\mu \mathrm{U} / \mathrm{ml}$ for plasma insulin, +++ indicates more than $2 \%$ sugar. Results are expressed as mean \pm S.E.M [n=6]. One-way ANOVA followed by post hoc test LSD. Values are statistically significant at @ $\mathrm{P}<0.05$; ${ }^{*} \mathrm{P}<0.01 ;{ }^{*} \mathrm{P}<0.001$. The results were compared with aControl rats, bDiabetic rats, cDiabetic rats treated with metformin. 
The levels of blood glucose and HbA1c \% were found to be significantly elevated in diabetic rats as compared with normal control. Oral administration of GOA 111 to diabetic rats significantly improved the altered level. The levels of plasma insulin were moderately decreased in HFD-STZ induced diabetic rats. Diabetic rats treated with GOA $111(300 \mathrm{mg}$ and $450 \mathrm{mg} / \mathrm{kg}$ b.w) and metformin showed improved insulin level.

Control rats did not show any significant variation in the blood glucose concentration throughout the experimental period. HFD-STZ induced diabetes results in chronic hyperglycemia, which was maintained throughout experimental period. In experimental rats, the levels of blood glucose, glycosylated hemoglobin were increased and the levels of hemoglobin, plasma insulin were decreased when compared with control group of rats. Upon oral administration with GOA 111 and metformin, these levels were reverted back to those of normal rats. Urine sugar which was present in the diabetic group of rats was found to be absent in GOA 111 as well as metformin treated groups of rats.

Glucose is an indispensable fuel for all cells and organs, but at the same time it leads to problems at high concentrations. As a consequence, blood glucose is controlled in a narrow range to guarantee constant supply and to avoid damages associated with elevated glucose levels. Liver is the main organ controlling blood glucose by (i) releasing newly synthesized or stored glucose in the blood stream when blood glucose is low, and (ii) using and storing glucose when blood glucose is elevated ${ }^{30}$.In the liver, defects in insulinstimulated hepatic glycogen synthesis and increased rates of hepatic gluconeogenesis are the main factors that contribute to insulin resistance and fasting hyperglycemia ${ }^{31}$.The blood glucose levels are significantly increased in diabetic group of rats which results from reduced glucose utilization by various tissues, which is a typical condition of insulinopenic ${ }^{32}$.A significant decrease in FBG levels in GOA 111 treated diabetic rats indicated that the GOA 111 has improved the insulin resistance in HFD-STZ induced diabetic rats

The HbA1c value reflects the average blood glucose over a 23 month period and has traditionally been used to evaluate the treatment of established DM. It has been described as a predictor for DM and of micro- and macrovascular disease 33,34,35,36. The HbA1c levels are the most reliable markers to assess the glycemic status of diabetic individuals over a period of 2- 3 month and prognostic value of the treatment ${ }^{37}$. Oral treatment with GOA 111 to diabetic rats significantly reduced the levels of $\mathrm{HbA1c}$ suggesting the beneficial effect of GOA 111 in maintaining glucose homeostasis.

Homeostatic model assessment (HOMA) is a method used to quantify insulin resistance and beta-cell function. HOMA-IR revealed impaired insulin tolerance in diabetic rats, which is associated with hyperinsulinemia. In type 2 diabetes, insulin resistance is a major factor that contributes to hyperinsulinemia and impaired insulin secretion. Due to decreased insulin response, $\beta$ cells secrete more insulin in response to the persistent hyperglycemia, resulting in hyperinsulinemia ${ }^{38}$. In the present study, HOMA IR value was reduced in diabetic rats treated with GOA 111 indicating improved insulin sensitivity. Figure 2 represents the effect of GOA 111 in lowering the insulin resistance in the different groups of rats. The results show significance both within the groups and between the groups.

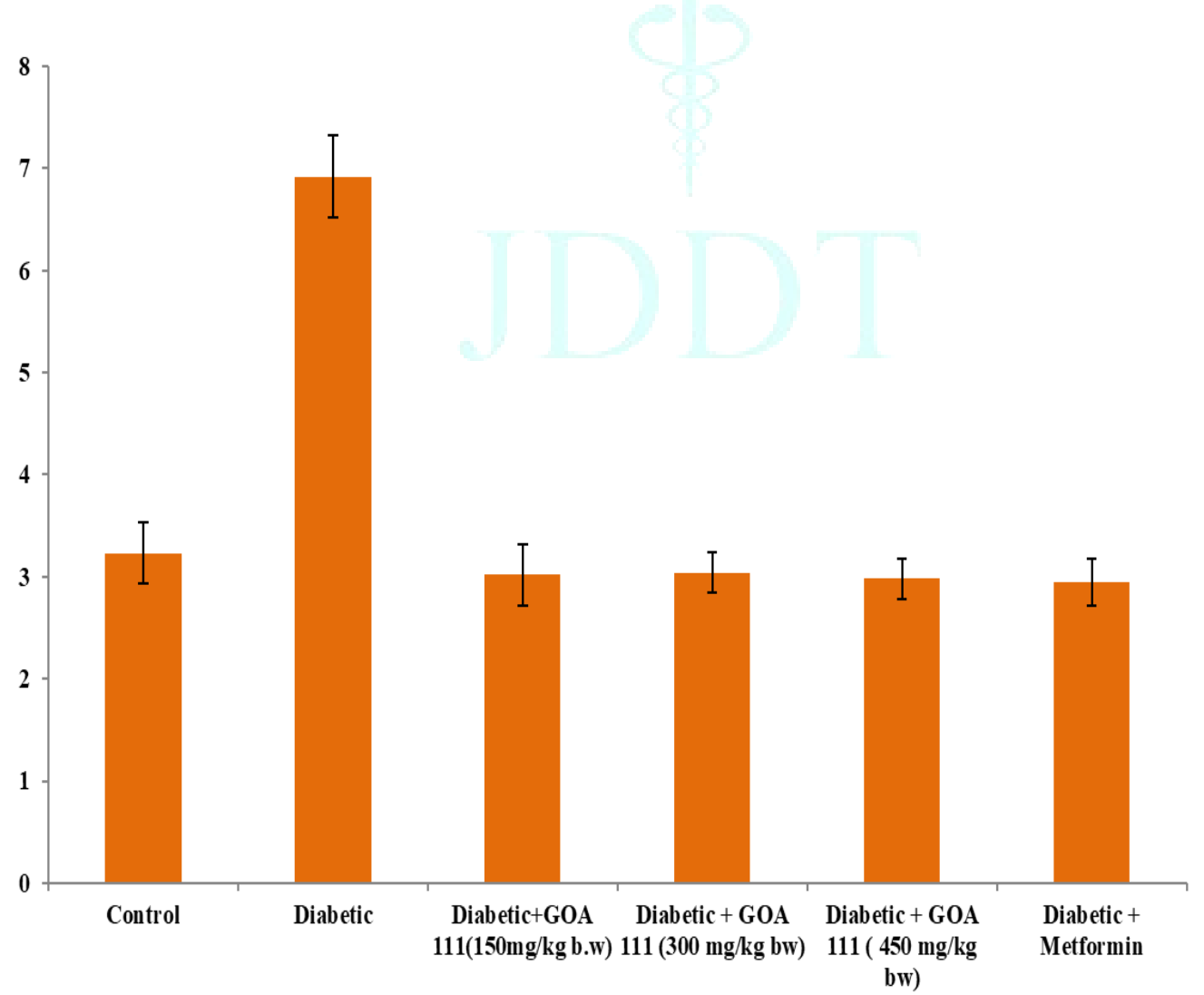

Results are expressed as mean \pm S.E.M $[\mathrm{n}=6]$. One-way ANOVA followed by post hoc test LSD. Statistical significance was compared within the groups as follows: "control rats; diabetic control rats. Values are statistically significant at $p<0.05$

Figure 2 : HOMA-IR of control, diabetic, diabetic treated with GOA 111 and metformin groups of rats 
Table 2 represents the effect of GOA 111 on the activities of serum AST, ALT and ALP in the experimental groups of rats. The pathophysiological indices in diabetic group of rats were significantly $(p<0.05)$ elevated as compared with control group of rats. Oral administration of GOA 111 to diabetic groups of rats significantly $(\mathrm{p}<0.05)$ normalized the altered levels in comparison with control group of rats. The results are comparable with the standard drug metformin.

Table 2: Effect of GOA 111 on the levels of activities of aspartate aminotransferase (AST), alanine aminotransferase (ALT) and alkaline phosphatase (ALP) in serum, liver and kidney tissues of control and experimental groups of rats.

\begin{tabular}{|l|c|c|c|}
\hline \multicolumn{1}{|c|}{ Groups } & AST & ALT & ALP \\
\hline Control & $87.21 \pm 3.10$ & $20.44 \pm 0.96$ & $75.10 \pm 3.10$ \\
\hline Diabetic control & $129.00 \pm 7.11^{\mathrm{a}^{*}}$ & $46.10 \pm 1.80^{\mathrm{a}^{*}}$ & $84.00 \pm 3.14 \mathrm{~b}^{*}$ \\
\hline $\begin{array}{l}\text { Diabetic + GOA 111 } \\
(150 \mathrm{mg} / \text { Kg.b.w) }\end{array}$ & $95.61 \pm 4.00^{\mathrm{b}^{*}}$ & $26.22 \pm 1.39 \mathrm{~b}^{*}$ & $81.30 \pm 3 . \mathrm{b}^{\mathrm{b}^{*}}$ \\
\hline $\begin{array}{l}\text { Diabetic + GOA 111 } \\
(300 \mathrm{mg} / \text { Kg.b.w) }\end{array}$ & $91.00 . \pm 3.18^{\mathrm{b}^{*}}$ & $25.16 \pm 1.50^{\mathrm{b}^{*}}$ & $80.10 \pm 3.00^{\mathrm{b}^{*}}$ \\
\hline $\begin{array}{l}\text { Diabetic + GOA 111 } \\
(450 \mathrm{mg} / \text { Kg.b.w) }\end{array}$ & $90.00 . \pm 3.24^{\mathrm{b}^{*}}$ & $25.00 \pm 1.40 \mathrm{~b}^{*}$ & $78.11 \pm 2.80 \mathrm{~b}^{*}$ \\
\hline Diabetic+metformin & $89.00 \pm 2.90 \mathrm{~b}^{*}$ & $22.21 \pm 1.38 \mathrm{~b}^{*}$ & \\
\hline
\end{tabular}

Liver, the key organ of metabolism and excretion, performs detoxification of xenobiotics, environmental pollutants, and chemotherapeutic agents. AST, ALT, ALP, are the major hepatic marker enzymes. The increased level of these enzymes is due to leakage from hepatocyte damage ${ }^{39}$. The elevation in AST and ALT activity can be regarded as an indicator for gluconeogenesis ${ }^{40}$. Oral administration of GOA 111 decreased AST and ALT levels indicating reduced gluconeogenesis.

The status lipid profile in experimental rats is presented in Figure 3. HFD-STZ diabetic rats showed increase in serum cholesterol, triglycerides and FFAs as compared with the control group. Oral treatment of GOA 111 decreased the levels of lipid profile.
Diabetes is associated with profound alterations in the plasma lipid and lipoprotein profile and with an increased risk of premature atherosclerosis, coronary insufficiency and myocardial infarction ${ }^{41}$. Hyperglycemia and the high level of insulin resistance that are characteristic with T2DM have multiple effects on fat metabolism, finally resulting in the production of atherogenic dyslipidemia. This is characterized by lipoprotein abnormalities: elevated very low density lipoprotein cholesterol (VLDL) elevated low density lipoprotein cholesterol (LDL-c), elevated triacylglycerol (TAG) and decreased high density lipoprotein cholesterol (HDL-c) which are measured for cardiovascular risk prediction 42,43 .

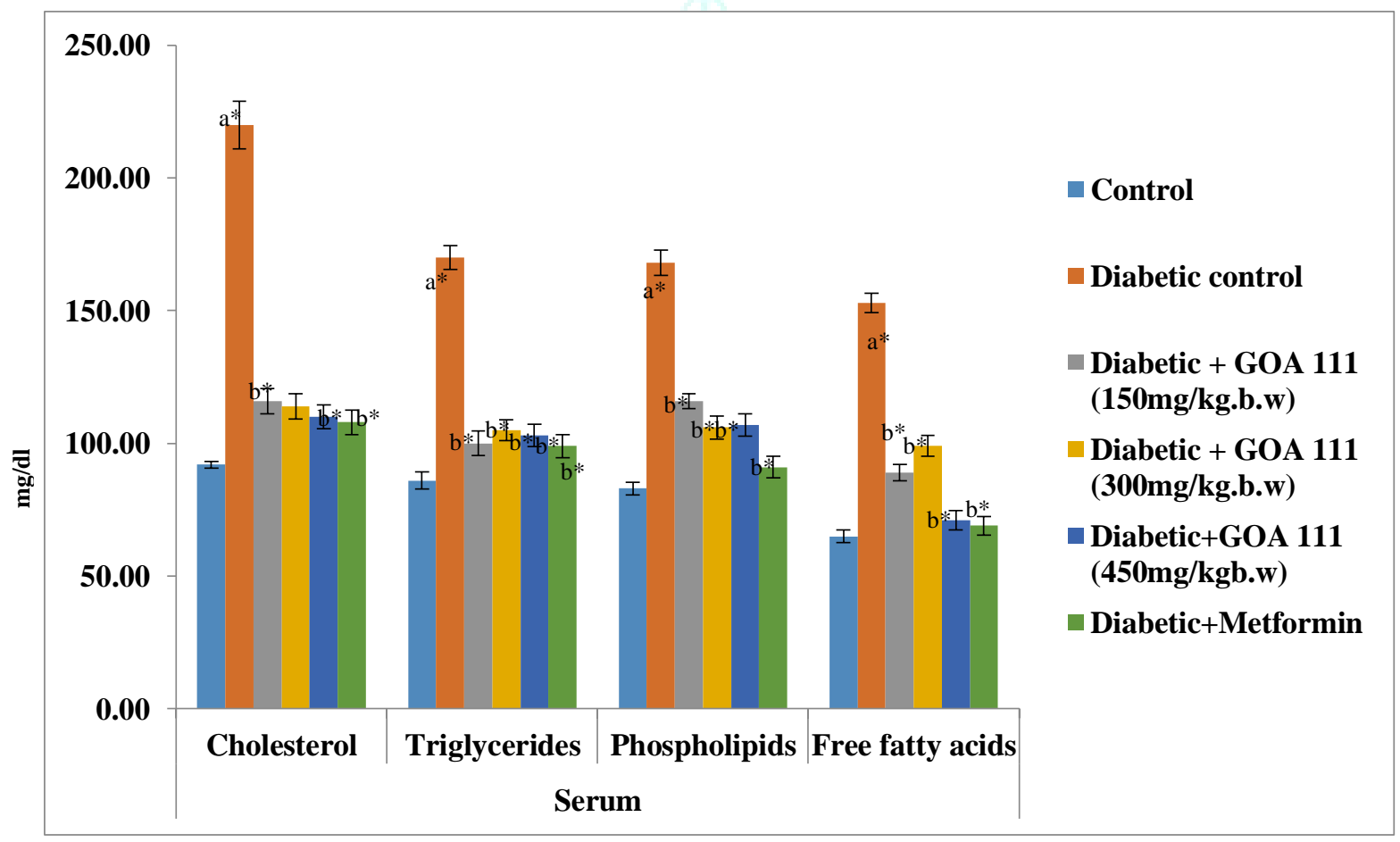

Figure 3: Effect of GOA 111 on serum lipid profile in experimental groups of rats 
The major pathogenesis of lipid metabolism disturbances in diabetes is the enhanced mobilization of free fatty acids from adipose tissue and secondary elevation of free fatty acid level in the blood 44 , as observed in the present study. The elevated level of serum lipids in diabetics is essentially due to increase in the mobilization of free fatty acids from the peripheral depots, since insulin inhibits the activity of hormone sensitive lipase. On the other hand, glucagon, catecholamines and other hormones enhance the lipolysis. Treatment with the GOA 111to diabetic rats resulted in the correction of hyperlipidemia and this may be attributed to the enhanced glucose utilization indicating its antidyslipidemic nature.

\section{CONCLUSION}

The results of the present study indicate that GOA 111 possesses antidiabetic and antidylipidemic properties. Polyherbal formulations having a mixture of several phytoingredients at various proportions from plant origin are often preferred because of their availability, accessibility, affordability, stability and safety. It is well understood that the mixture of various phytoingredients present in GOA 111 are claimed to display synergistic and efficacious actions and the mixture of species in them shows better therapeutic effect relatively at a lesser concentration than either species on its own.

\section{REFERENCES}

1. DeFronzo RA et al., 2015. Type 2 diabetes mellitus. Nature Reviews, Disease Primers, 1: 15019

2. Bai L, Li X2, He L2, Zheng Y1, Lu H1, Li J1, Zhong L1, Tong R1, Jiang Z3, Shi J1, Li J4. Antidiabetic Potential of Flavonoids from Traditional Chinese Medicine: A Review. Am J Chin Med. 2019 Jun 27:1-25.

3. Alam F, Islam MA, Kamal MA, Gan SH. Updates on Managing Type 2 Diabetes Mellitus with Natural Products: Towards Antidiabetic Drug Development. Curr Med Chem. 2018;25(39):5395-5431.

4. Ghorbani A.Clinical and experimental studies on polyherbal formulations for diabetes: current status and future prospective. J Integr Med. 2014 Jul;12(4):336-45. doi: 10.1016/S2095-4964(14)60031-5.

5. Thakur GS., Bag M., Sanodiya BS., et al. Chlorophytum borivilianum: A White Gold for Biopharmaceuticals and Neutraceuticals. Curr Pharm Biotechnol. 2009; 10: 650-666.

6. Sanodiya BS., Thakur GS., Baghel RK., et al. Ganoderma lucidum: A Potent Pharmacological Macrofungi. Curr Pharm Biotechnol. 2009; 10: 717-742.

7. Singh S, Malhotra M, Majumdar DK Antibacterial activity of Ocimum sanctum L. fixed oil.Indian J Exp Biol. 2005 Sep; 43(9):835-7.

8. Narendhirakannan RT, Subramanian S, Kandaswamy M. Biochemical evaluation of antidiabetogenic properties of some commonly used Indian plants on streptozotocininduced diabetes in experimental rats. Clin Exp Pharmacol Physiol. 2006 Dec; 33(12):1150-7.

9. Sood S, Narang D, Thomas MK, Gupta YK, Maulik SK. Effect of Ocimum sanctum Linn. on cardiac changes in rats subjected to chronic restraint stress. J Ethnopharmacol. 2006 Dec 6; 108(3):423-7.

10. Gupta S, Mediratta PK, Singh S, Sharma KK, Shukla R. Antidiabetic, antihypercholesterolaemic and antioxidant effect of Ocimum sanctum (Linn) seed oil. Indian J Exp Biol. 2006 Apr;44(4):300-4.

11. Bhattacharyya $P$, Bishayee A. Ocimum sanctum Linn. (Tulsi): an ethnomedicinal plant for the prevention and treatment of cancer. Anticancer Drugs. 2013 Aug;24(7):659-66.

12. Subapriya R, Nagini S. Medicinal properties of neem leaves: a review. Curr Med Chem 2005; 5: 149-146.

13. Mahfuzul Hoque MD, Bari ML, Inatsu Y, Juneja VK, Kawamoto S. Antibacterial activity of guava (Psidium guajava L.) and Neem (Azadirachta indica A. Juss.) extracts against foodborne pathogens and spoilage bacteria. Foodborne Pathog Dis. 2007 Winter;4(4):481-8.
14. Srinivasan K, Viswanad B, Asrat L, Kaul CL, Ramarao P. Combination of high-fat diet-fed and low-dose streptozotocintreated rat: a model for type 2 diabetes and pharmacological screening. Pharmacol Res. 2005; 52 (4): 313- 320.

15. Trinder P (1969). Determination of blood glucose using an oxidaseperoxidase system with a non-carcinogenic chromogen. J Clin Pathol, 22 (2):158-161.

16. Drabkin DL, Austin JM. Spectrophotometric constants for common hemoglobin derivatives in human, dog and rabbit blood. J Biol Chem. 1932; 98: 719-733.

17. Nayak SS, Pattabiraman TN. A new colorimetric method for the estimation of glycosylated hemoglobin. Clin Chem Acta. 1981; 109: 267-274.

18. a) King J. The transaminases: alanine and aspartate transaminases. In: Practical Clinical Enzymology (ed.) D.Van, Nostrand Co., London. 1965a; pp. 363-395.

18 b) King J. The hydrolases-acid and alkaline phosphatases. In : Practical clinical enzymology. (Ed.) Van D. Nostrand Co, London. 1965b; pp.199-208.

19 Matthews D, Hosker J, Rudenski A, Naylor B, Treacher D, Turner R. Homeostasis model assessment: insulin resistance and beta cell function from fasting plasma glucose and insulin concentrations in man. Diabetologia. 1985; 28:412-419.

20 Parekh AC, Jung DH. Cholesterol determination with ferric acetate uranyl acetate and sulphuric acidferrous sulphate reagents. Anal Chem. 1970; 42: 1423-1427.

21 Foster LB, Dunn RT (1973). Stable reagents for determination of serum triglycerides by a colorimetric Hantzsch condensation method. Clin Chem. 19(3):338-40.

22 Itaya K. A more sensitive and stable calorimetric determination of free fatty acids in plasma. J Lip Res. 1977; 18: 663-665.

23 Bartlette GR (1959). Phosphorous assay in column chromatography. J Biol Chem. 234 (3): 466-468.

24 Fiske CH, Subbarow Y (1925). The colorimetric determination of phosphorus. J Biol Chem. 66: 375-400.

25 Petersen KF, Dufour S, Feng J, Befroy D, Dziura J, Dalla Man C, Cobelli C, Shulman GI. Increased prevalence of insulin resistance and nonalcoholic fatty liver disease in Asian-Indian men. Proc Natl Acad Sci U S A. 2006 Nov 28;103(48):18273-7. Epub 2006 Nov 17.

26 Zhang M, Lv XY, Li J, Xu ZG, Chen L (2008).The characterization of high-fat diet and multiple low-dose streptozotocin induced type 2 diabetes rat model.Exp Diabetes Res2008:704045.

27 Rojas LB, Gomes MB. Metformin: an old but still the best treatment for type 2 diabetes. Diabetol Metab Syndr, 2013; 5(1):6.

28 Yu EY, Wong CK, Ho SY, Wong SY, Lam CL. Can HbA1c replace OGTT for the diagnosis of diabetes mellitus among Chinese patients with impaired fasting glucose? Fam Pract. 2015 Dec;32(6):631-8.

29 29.Alberti, K.G. and Zimmet, P.Z. (1998) Definition, Diagnosis and Classification of Diabetes Mellitus and Its Complications. Part 1: Diagnosis and Classification of Diabetes Mellitus Provisional Report of a WHO Consultation. Diabetic Medicine, 15, 539-553.

30 König M, Bulik S, Holzhütter HG. Quantifying the contribution of the liver to glucose homeostasis: a detailed kinetic model of human hepatic glucose metabolism. PLoS Comput Biol 2012; 8(6):e1002577.

31 Erion DM, Shulman GI. Diacylglycerol-mediated insulin resistance. Nat Med. 2010; 16(4): 400-402.

32 Mann CJ, Ayuso E, Anguela XM, Bosch F. Skeletal muscle metabolism in the pathology and treatment of type 1 diabetes. Curr. Pharm. Des. 2010; 16: 1002-1020.

33 van Leiden HA, Dekker JM, Moll AC, Nijpels G, Heine RJ, Bouter LM. Risk factors for incident retinopathy in a diabetic and nondiabetic population: the Hoorn study. Arch Ophthalmol. 2003;121:245-251.

34 Tapp RJ, Tikellis G, Wong TY, Harper CA, Zimmet PZ, Shaw JE. Longitudinal association of glucose metabolism with retinopathy: results from the Australian Diabetes Obesity and Lifestyle (AusDiab) study. Diabetes Care. 2008;31:1349-1354.

35 Selvin E, Ning Y, Steffes MW, Bash LD, Klein R, Wong TY. Glycated hemoglobin and the risk of kidney disease and 
retinopathy in adults with and without diabetes. Diabetes. 2011;60:298-305.

36 Sabanayagam C, Liew G, Tai ES, Shankar A, Lim SC, Subramaniam T. Relationship between glycated haemoglobin and microvascular complications: is there a natural cut-off point for the diagnosis of diabetes? Diabetologia. 2009;52:1279-1289. doi: 10.1007/s00125-009-13605.[PubMed] [CrossRef] [Google Scholar]

37 Nathan DM, Turgeon H, Regan S. Relationship between glycated haemoglobin levels and mean glucose levels over time. Diabetologia. 2007; 50: 2239-2244.

38 Shanik MH, Xu Y, Skrha J, Dankner R, Zick Y, Roth J. Insulin resistance and hyperinsulinemia: is hyperinsulinemia the cart or the horse? Diabetes Care. 2008; 31 suppl 2:S262-8.

39 Loria P, Lonardo A, Carulli L, Verrone AM, Ricchi M, Lombardini S, Rudilosso A, Ballestri S, Carulli N (2005).
Review article: the metabolic syndrome and non-alcoholic fatty liver disease. Aliment Pharmacol Ther 22:31-36

40 Rubio-Tapia A, Murray JA. The liver in celiac disease. Hepatology. 2007;46(5):1650-1658.

41 Reasner CA: Reducing cardiovascular complications of type 2 diabetes by targeting multiple risk factors. J Cardiovasc Pharmacol. 2008; 52(2):136-144.

42 Grundy SM, Cleeman JI, Merz CN, Brewer HB, Jr, Clark LT, Hunninghake DB. Implications of recent clinical trials for the National Cholesterol Education Program Adult Treatment Panel III guidelines. Circulation. 2004;110(2):227-239.

43 Nigam PK. Serum Lipid Profile: Fasting/Non-fasting? Ind J Clin Biochem. 2011;26(1):96-97.

44 Guilherme A, Virbasius JV, Puri V, Czech MP. Adipocyte dysfunctions linking obesity to insulin resistance and type 2 diabetes. Nat Rev Mol Cell Biol. 2008; 9(5):367-377. 